\title{
Understanding reasons for non-adherence to active surveillance for low-intermediate risk prostate cancer
}

\author{
Kerri Beckmann ${ }^{1,2}$, Declan Cahill ${ }^{3}$, Christian Brown ${ }^{4}$, Mieke Van Hemelrijck ${ }^{1}$, Netty Kinsella ${ }^{1,3}$ \\ ${ }^{1}$ Translational Oncology and Urology Research, Kings College London, London, UK; ${ }^{2}$ Cancer Research Institute, University of South Australia, \\ Adelaide, Australia; ${ }^{3}$ Department of Urology, The Royal Marsden Hospital, London, UK; ${ }^{4}$ The Urology Centre, Guy's and St Thomas' NHS \\ Foundation Trust, London, UK \\ Contributions: (I) Conception and design: N Kinsella, M Van Hemelrijck; (II) Administrative support: not applicable; (III) Provision of study materials \\ or patients: D Cahill, C Brown; (IV) Collection and assembly of data: N Kinsella; (V) Data analysis and interpretation: N Kinsella, K Beckmann, M \\ Van Hemelrijck; (VI) Manuscript writing: All authors; (VII) Final approval of manuscript: All authors. \\ Correspondence to: Dr. Kerri Beckmann. Cancer Research Institute, University of South Australia, Level 8 SAHMRI Building, North Terrace, Adelaide \\ SA 5001, Australia. Email: kerri.beckmann@unisa.edu.au; kerri.beckmann@kcl.ac.uk.
}

Background: Active surveillance (AS) is recommended by most national medical organizations as the preferred treatment option for men with low-risk prostate cancer (PCa). However, studies report that up to one third of men on AS dropout within 5 years, without evidence of disease progression. Despite high dropout rates, few studies have purposively explored the opinions and experiences of men who discontinued AS. The aim of this study was to gain insight into the reasons why some men on AS for PCa discontinue active treatment without evidence of disease progression.

Methods: Semi-structured interviews were undertaken with 14 men from diverse socio-cultural backgrounds who had been on AS for PCa but dropped out of surveillance to undergo active treatment without signs of disease progression. Purposive sampling to reach data saturation was used to select participants based on their experience of AS and willingness to share their experiences. Interviews were transcribed and analysis undertaken in an inductive thematic manner.

Results: The following themes arose from interviews as factors that potentially influence adherence to AS: men's experience at diagnosis and follow-up consultations, involvement in shared decision-making, the extent of supportive care and information, administrative procedures and support from partner and peers. A poor experience during diagnosis could adversely influence long-term adherence to AS, given the same diagnostic tests are frequently repeated. The provision of consistent information and support while on AS, similar to that offered to men undergoing radical treatment, was also highlighted as being important to increase confidence in the process.

Conclusions: Effective communications skills among health professionals, aimed at building trust in patient-clinician relationships, providing opportunities for shared decision-making and developing selfefficacy, along with structured information and support, are key to enhancing long-term adherence to AS.

Keywords: Prostate cancer (PCa); active surveillance (AS); adherence; qualitative research

Submitted Sep 11, 2020. Accepted for publication Feb 04, 2021.

doi: $10.21037 /$ tau-20-1254

View this article at: http://dx.doi.org/10.21037/tau-20-1254 


\section{Introduction}

European, US and Australian guidelines on the management of prostate cancer $(\mathrm{PCa})$ state that most men with localized, low risk disease do not require immediate treatment, but instead can be monitored through active surveillance (AS) (1-4). However, lack of standard protocols for inclusion and follow-up (5), among other patient, support and health-care provider factors (6-8), are likely to contribute to the high proportion of men dropping out (up to $38 \%$ ) of AS without evidence of disease progression (9).

Our recent systematic review of literature on facilitators and barriers to AS choice and adherence identified factors pertaining to five themes including (I) cancer characteristics; (II) patient perceptions, (III) family and peer support, (IV) health care providers role, $(\mathrm{V})$ organisational/practice issues, and (VI) health policy (10). Key issues include control of decision making/self-management, pressure from family friends and peers, consistent information and support and clarity in terms of AS policies/practice. We also identified gaps in the literature with respect to identifying reasons for non-adherence, particularly in relation to hearing directly from men who dropped out of AS about their reasons for their choice.

The aim of this study was to gain further insight into the reasons why some men on AS for PCa choose to convert to active treatment without any evidence of disease progression. To this end we undertook qualitative interviews to explore the views of men who dropped out of AS (despite a lack of evidence of disease progression). We present the following article in accordance with the MDAR reporting checklist (available at http://dx.doi.org/10.21037/tau-20-1254).

\section{Methods}

The Royal Marsden NHS Trust's Quality Improvement Project Committee approved this study as a component of a larger project directed toward developing a new information and supportive care programme for men on AS. The study was conducted in accordance with the Declaration of Helsinki (as revised in 2013). The study was approved by institutional review committee (Royal Marsden Hospital) and informed consent was taken from all individual participants.

\section{Qualitative interviews}

A semi-structured interview guide was designed according to the framework developed by Kallio and colleagues (11). This process included: (I) identifying the most appropriate interview technique; (II) retrieving and using previous knowledge; (III) formulating a preliminary semi-structured interview guide; (IV) pilot testing the guide; and (V) developing the final semi-structured interview guide.

The outcomes from our previous systemic review (10) were used to develop the interview guide which was first piloted with four patients on AS for between 18 to 48 months. Issues identified in the pilot phase included previous time on AS, the specific venue for interviews and details of the interview guide. Consequently, only patients on AS for 24 months or more were invited to participate, and the interview environment was changed to more private patient liaison offices. The final interview guide was reviewed by the Active Surveillance Reference Group (ASRG) before final application.

Semi-structured interview techniques consisted of openended questions prompted by the topic guide (12) (Table 1). Topics explored included: mens' experiences of their diagnosis of $\mathrm{PCa}$, their perceptions and any concerns about the process, personal factors, cancer characteristics, family and social support, interaction with health care providers and, organisational and policy issues. Interviews generally lasted between 18 and 45 minutes and were all conducted by a single Nurse Consultant (NK). Interviews were recorded with participants' permission and transcribed in a 'clean verbatim' style excluding stutters, fillers and false starts (13). Full written consent was obtained in line with the Department of Health's Research Governance Framework for Health and Social Care (14).

Inductive thematic analysis of interview transcripts was undertaken whereby all datasets were read and reread, by a single researcher NK, to search for emerging themes ('funnelling') (15). A coding structure developed to facilitate the identification of patterns within the transcripts which were condensed into themes. This iterative process continued until a coherent analysis was developed. A summary of the key emergent themes was sent to respondents for their comments as further validation of our synthesis. Respondents consistently reported that the summary accurately represented their views.

\section{Results}

All interview participants had been diagnosed and managed at the same treatment centre by the same Uro-oncology clinical team. Four out of the 18 men who agreed to be interviewed about their experiences subsequently withdrew from the study for personal reasons. The remaining group 
Table 1 Interview topic guide derived from systematic review (Kinsella 2018)

\begin{tabular}{ll}
\hline Category & Topic guide \\
\hline $\begin{array}{l}\text { Experience of prostate } \\
\text { cancer diagnosis and } \\
\text { treatment }\end{array}$ & $\begin{array}{l}\text { Experience of diagnosis and treatment planning (perceptions and any concerns), factual details of diagnosis, } \\
\text { reasons for choosing AS, reasons for dropping out of AS, general facilitators and barriers whilst on AS }\end{array}$ \\
Patient factors & $\begin{array}{l}\text { Perceived risk, shared decision making, specific patient characteristics, lifestyle factors, side effects, } \\
\text { preference }\end{array}$ \\
Cancer characteristics & $\begin{array}{l}\text { Understanding progression, stage, Gleason grade, PSA, tumour volume } \\
\text { Family and social support }\end{array}$ \\
Provider & $\begin{array}{l}\text { Awareness + acceptance, fear of progression, advice from family, friends and peer group } \\
\text { recommendation, Information and support }\end{array}$ \\
Health organisation & Practice site, differences/changes in as strategy, multi-disciplinary clinic, formal shared decision-making \\
Health policy & Guidelines, trial and cohort data, awareness and acceptance by medical community \\
\hline
\end{tabular}

Table 2 Characteristics of participants

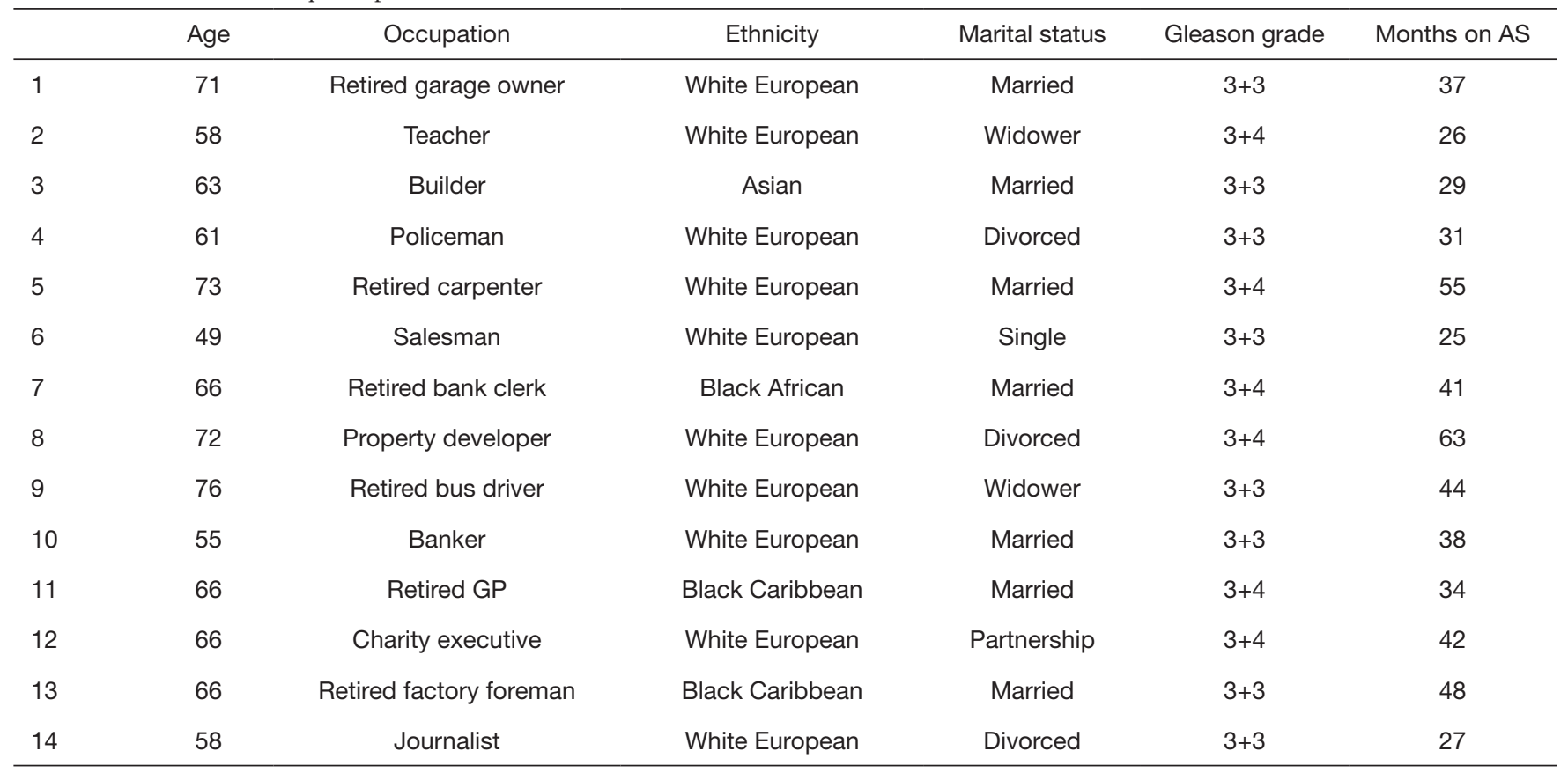

of men ( $\mathrm{n}=14)$ varied in age, background and ethnicity; reflective of the local population (Table 2). The mean age of participants was 64 years (49 to 76 years), mean time on AS was 39 months (25 to 63 months) and mean PSA was $5 \mu \mathrm{g} / \mathrm{L}$ (range 2 to $8 \mu \mathrm{g} / \mathrm{L}$ ). Twenty-nice percent of participants were of Asian, African, Afro-Caribbean ethnicity, reflecting the diverse ethnicity of London (16). The influence of time on AS was taken into consideration in the analysis. Saturation was judged to have been reached after nine interviews, despite 14 interviews in total being undertaken.

A range of recurring recollections, feelings and opinions were revealed throughout the interviews. The issue that were raised are grouped and described according to the following themes: (I) patient experience of consultations at diagnosis and follow-up; (II) shared decision making; (III) support and information needs; (IV) administration and organisational issues; (V) partner, family and peer support. Figure 1 summarises the key findings. 


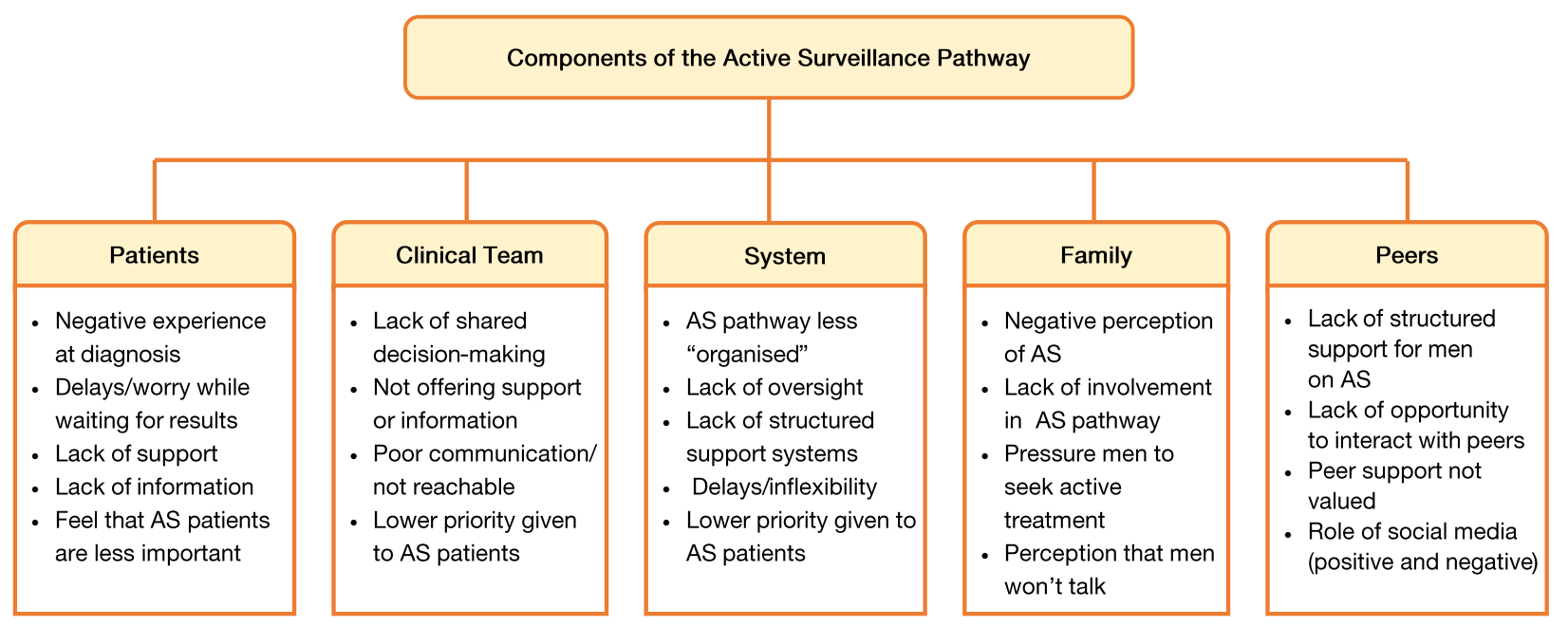

Figure 1 Schema of the summative findings: factors influencing non-adherence to active surveillance for prostate cancer.

\section{Experience of consultations (diagnosis and follow-up)}

A common theme across interviews was the impact of negative experiences during diagnostic procedures, which were highlighted as being among the most difficult of their entire PCa experience.

'...you don't know what's going on because there is no support until after the diagnosis.

For many participants the diagnostic process was long and drawn out, with direct comparison made between the process of diagnosis and follow-up procedures while on AS.

"...At diagnosis my scan took three weeks and my biopsy results took four weeks. I almost missed my appointment because the letter arrived the morning of the appointment by which point I was climbing the walls...It was just the same once I'd started on active surveillance-I couldn't deal with it..."

"Although active surveillance was attractive, I just couldn't go through the waiting every 12-18 months. It drove me crazy after the second lot of biopsies so I chose to have surgery. I just think they could sort this out so easily-its customer service. Good service and people are happy..."

\section{Shared decision making}

Many men described the process of shared decision making as being quite limited.

“...It was confusing. I read that there were new guidelines on active surveillance and the doctor told me they weren't relevant to me as I was part of an active surveillance trial. I just wanted to discuss the implications of the guidelines, was it better or worse than the care I was getting..."

“...They didn't seem to want me to participate in the consultation; I felt as I they expected me to just agree to whatever they suggested, with the briefest of explanations. I'm a professional; I wouldn't expect my clients to agree to something just because I told them to do it. I think the NHS is out of step with the rest of the world in 2017!..."

\section{Support and information needs}

Participants consistently indicated that they required information and support throughout all stages of their encounter with $\mathrm{PCa}$, including: psychological support, descriptive information, AS research data and strategies for self-care. They also mentioned preferring to discuss rather than read information.

“...Whilst there was plenty to read on the internet, it's finding people that have been through it that I found most belpful. ... Often you can read and read but, at the end of the day, talking to someone, is the most important part..."

Several participants indicated that they had not been offered psychological support while on AS, though they felt it was would have been helpful for coping or adjusting to their PCa diagnosis.

“...I just needed someone to off-load on. I couldn't get through on the phone... when I did, my nurse asked me what I was fussing over. I heard about the hospital psychological support services during my radiotherapy... Too little, too late!...”

"...I felt like I did when I went through my breakdown in 92, I'd lost control, I was spiralling. I think if they'd recognised this I 
could have got the belp I needed...I saw my GP, be recommended that I had treatment - it was the best advice I'd been given since my diagnosis 3 years earlier, once I'd made the decision the weight lifted..."

Participants also felt that the clinical team lacked enthusiasm for AS.

"...I asked the doctor for some references to the latest active surveillance research. He said there wasn't anything useful, be sounded so bored by the question. I did my own research; there was lots that interested me. I'm an engineer; I like to know bow these things work. In my line of work if an engineer isn't engaged and interested in what he's doing mistakes happen, I couldn't risk it, it's my life..."

Several participants noted the difference in their experience after choosing to have active treatment.

"...From the moment I choose active surveillance to the day I choose to have treatment, I didn't see the consultant-that was 2 and a balf years!..."

"...I chose radiotherapy, from that moment I was introduced to my Nurse specialist and a support worker, I also met a specialist radiographer who was going to see me every week during my treatment. They sent me to a seminar...where I met more of the team and lots of other patients...that was to prepare me for treatment. I couldn't have felt more love and support. I didn't feel nervous about the treatment at all. If they had done the same for surveillance I might not have had treatment..."

\section{Administrative and organisational issues}

Participants frequently described the lack of oversight in relation to the complicated process of AS.

"...Suddenly be (the consultant) was interested in me. He said be would see me next time. In all the time that they were monitoring me (4 years) I'd only seen him once. It had been a different junior doctor every time. I just didn't have the confidence to go on with that...If I'd seen him once a year even...I think that would have been enough..."

"...I would go to the effort of re-organising my scans so that they fitted around my appointments as often the scan date fell after the appointment, and then the hospital would call or send a letter cancelling the clinic. ... That's definitely an area they could improve: at least reassuring the patient that their scan was ok, instead of leaving them in limbo..."

While many respondents praised the responsiveness of the clinical nurse specialists, they often felt nurses had little power to change the service model.

"...I called my nurse, she was lovely and apologetic but explained that there was no way of bringing my appointment forward as the scanner was back to back with people and the theatre lists were all full... It was good to know the situation but bardly reassuring. I remember that at least 2 of my scans were cancelled and my biopsy date was pushed back...I felt like this was a big cancer centre trying to 'deal' with a group of patients that didn't fit the normal 'cancer patient' stereotype. I even heard people referring to us (patients on active surveillance) as the 'worried well'..."

Some participants indicated that the process might be more efficient if their follow-up consultation was via a telephone call rather than a face-to-face appointment.

“...the doctor said be would ring me in a couple of days. A week went by so I rang the hospital and asked what was going on. I was told that the doctor would call me as soon as be was available as the nurse 'wasn't allowed' to give results over the phone...I wasn't very happy with that, I felt that anybody facing a possible cancer diagnosis is going to be stressed...so to leave me sitting there like a mug..."

"...When I had to go for the MRI scan, I would be very anxious waiting for those results because it often took weeks to hear from the hospital. I don't know how long it takes for someone to review these things but if they knew how we felt waiting perhaps it wouldn't take so long. I felt quite resentful, like my cancer was being de-prioritised because it didn't need treatment..."

\section{Partner, family and peer support}

Interviewees also felt that the perception that men preferred not to discuss 'personal' issues with one another was perhaps an outdated stereotype perpetrated throughout the media rather than a reality.

"...I even caught my wife saying it to our daughter. She said 'you know what men are like, he just won't talk about it', I did though, I just didn't know what to say to her. I wanted to chat to someone who was going through the same thing..."

Their accounts of discussing their experience of $\mathrm{PCa}$ with other men where ever possible, particularly at informal events and over social media, challenged this stereotype.

“...I'd never tweeted before but I'd had an account for a while... mainly to follow my kids. I decided to reply to a tweet from one of the cancer charities, when I did I was overwhelmed by the response and feeling of support...I'm now tweeting about 3-4 times per day. I try to give support to others rather than getting into anything controversial, but it works, it belps, I feel better..."

Many men felt that the opportunity to talk more with other men in hospital (in waiting rooms, on wards etc.) could have greatly improved the AS experience. 
"...I went to the hospital with my mate, the waiting area had volunteers in it, they were chatting to people as they came through the door and answering any questions. I found out that they'd all been diagnosed with cancer and treated at the hospital. One chap had had his prostate removed a few months before. He couldn't stop praising the team, hospital and the experience. He looked so well, it spurred me on to having treatment. I think if I'd met someone that had been on surveillance for a few years I might have stuck with it..."

In some cases, the value of this interaction was recognized only after sharing a hospital room with another man following surgery for their PCa.

"....He really is one of my closest friends now. Having your prostate out is such a strange thing to bond over, but every appointment after our surgery we did together. It gives me a lift. I wish they'd had some way of putting men in touch with each other when I was diagnosed..."

Many men described the significant influence their partners had on their decision making. as the most difficult element to balance while remaining on AS.

"...My wife wanted me to have treatment, she never wavered. To be honest, she wore me down. I went for surgery because she wanted it, not because I did. If I'd been on my own I'd still be monitored..."

\section{Discussion}

Our qualitative study describes the experiences of men on AS for PCa who opted out despite no evidence of progression. Findings suggest that experiences at diagnosis and follow-up consultations, involvement in the decisionmaking process, the extent of support and information provided, organizational processes, and level of partner and peer support can affect adherence to AS.

Given that the process of AS involves frequently repeating the same tests as at diagnosis to monitor progression, a negative experience during diagnosis could adversely affect both the initial uptake and long-term adherence to AS. Strategies to expedite diagnostic and subsequent surveillance procedures for PCa should consider how best to reduce the psychological morbidity associated with waiting for diagnosis/test results over an extended period of time when little supportive care is available. Co-ordination between specialist hospital teams and GPs to develop a means of checking on patients' mental wellbeing during diagnosis and providing psychological support where necessary, may serve to reduce distress during the diagnostic phase (17) and minimise the psychological burden of adhering to AS where repeated investigations are required.

Although interest in decision making varies among patients, many men value involvement in the process (18). Where patients are not able to actively participate, rates of treatment adherence are known to suffer (19). Interviews indicated that for many participants their orientation toward involvement in cancer management changed over time. Failure of the clinical team to respond to men's changing needs was indicated by more than two thirds of participants as a reason for opting out of AS. Thus, a key step toward improving adherence is to encourage health care professionals to vary their approach to shared decisionmaking in accordance with patients' changing needs during the course of AS.

Engaging partners and family in consultations can serve to strengthen both the decision to undergo AS and long-term adherence to this management approach by creating a positive therapeutic alliance (20-23). Given good communication is crucial for building trust in the clinician and the system, creating shared understanding, developing self-efficacy will ultimately encourage long-term adherence to AS (24-26). Health care professionals involved in managing AS patients might therefore benefit from training to improving their communication skills.

There was a clear disparity between the views of men with $\mathrm{PCa}$ and health care professionals regarding men's need for support and information whilst on AS (27). While individual patients differ in the level of information and support that they wish to receive, so too do clinicians fluctuate in relation to how much they provide. Meeting the patients' information needs can increase overall satisfaction (28), facilitate participation during consultations (29), enhance the patient's ability to cope with illness (30) and promote higher levels of trust in clinicians (31), all of which can improve adherence behavior (18).

Interview participants highlighted the stark differences in the provision of information and supportive care once they decided to undergo radical treatment. This may be due to the recent focus on multimodal 'prehabilitation' programmes for cancer patients before treatment which provide patients with self-management strategies that empower them and ultimately lead to improved health outcomes (32). Of particular relevance to AS is the application of a chronic care model (33), which aims to improve the quality of life for those living with cancer through self-management support, alongside delivering decision support, organizational change, and community resources $(34,35)$. This approach is one to consider where the goal is to improve adherence to 
surveillance in order to reduce the physical and emotional burden of over-treatment of low risk PCa.

Participants also commented on the "old stereotype" that men were uncomfortable discussing 'personal' issues with peers and family members. They openly challenged this by discussing their experience of AS with any man who would listen, including at informal events and through social media. Many participants also indicated that, due to spending less time in hospital exposed to others going through the same process, they missed out on opportunities to share experiences with other men. One suggested mechanism for peer support is to provide forums that encourage open discussion of problems in a supportive environment and promote peer learning (36). Consideration should therefore be given to providing peer support opportunities for men on AS, either via face to face support groups or web based groups (37).

Finally, participants highlighted the need for more efficient administrative processes for appointments that allow easy movement between services such as imaging and biopsy, and reduce uncertainty and helplessness arising from delayed or cancelled appointments. Delays in healthcare processes can greatly affect patient experience and satisfaction (23). Healthcare providers and health systems should therefore aim to provide a more 'patientcentred' approach, whereby care is delivered in a way that meets patients' needs (38). While this could be achieved by encouraging greater patient participation in this process (39) structural changes within the health care setting, for example to reduce waiting times, are also required (40).

While acknowledging that limited resources and staffing issues may be barriers to addressing the issues raised in these interviews, some practical approaches could include offering telephone/virtual consultations and personalizing follow-up (e.g., offering less intense monitoring schedules to those who have stable disease). Adopting a more personalized approach to care has been shown to improve patient satisfaction while still being robust, efficient and cost effective (41).

\section{Strengths and limitations}

Qualitative interviews are limited by the respondents' ability to accurately recall their thoughts, opinions and behaviours. Participants recollections and perceptions can change and be re-appraised over time. Some interview participants may have placed more importance on being viewed as a 'good patient' (42) and, not wishing to appear to be complaining about their treatment whilst on AS, have tailored their accounts accordingly (43). However, qualitative interviews provide participants with the opportunity to elaborate in a way that is not offered through other qualitative methods such as survey research. Interview methods enable participants to share their experiences in their own words and from their own perspectives rather than adapting their perspectives to fit into limited response options.

\section{Conclusions}

Negative experiences at diagnosis, delays and inflexibility at follow-up appointments, inaccessibility of the health care team, lack of information and support, not being able to connect with peers, being excluded from shared decision making and perceptions of being considered a low priority patient were identified as reasons why some men choose to discontinue AS despite no signs of disease progression. The provision of structured information and support, improved communication and incorporation of shared decisionmaking by health care providers could go some way to addressing the unmet needs of men on AS for PCa and ultimately serve to increase long term adherence.

\section{Acknowledgments}

Authors would like to acknowledge the advice and guidance provided by members of the Active Surveillance Reference Group and the generosity of all study participants who consented to being interviewed.

Funding: None.

\section{Footnote}

Provenance and Peer Review: This article was commissioned by the editorial office, Translational Andrology and Urology, for the series "Expectant Management in Genitourinary Malignancies (Prostate, Bladder, Kidney)". The article has undergone external peer review.

Reporting Checklist: The authors have completed the MDAR reporting checklist. Available at http://dx.doi.org/10.21037/ tau-20-1254

Data Sharing Statement: Available at http://dx.doi. org/10.21037/tau-20-1254

Conflicts of Interest: The authors have completed the 
ICMJE uniform disclosure form (available at http:// dx.doi.org/10.21037/tau-20-1254). The series "Expectant Management in Genitourinary Malignancies (Prostate, Bladder, Kidney)" was commissioned by the editorial office without any funding or sponsorship. Drs. NK and MVH served as the unpaid Guest Editors of the series. The authors have no other conflicts of interest to declare.

Ethical Statement: The authors are accountable for all aspects of the work in ensuring that questions related to the accuracy or integrity of any part of the work are appropriately investigated and resolved. The study was conducted in accordance with the Declaration of Helsinki (as revised in 2013). The study was approved by institutional review committee (Royal Marsden Hospital) and informed consent was taken from all individual participants.

Open Access Statement: This is an Open Access article distributed in accordance with the Creative Commons Attribution-NonCommercial-NoDerivs 4.0 International License (CC BY-NC-ND 4.0), which permits the noncommercial replication and distribution of the article with the strict proviso that no changes or edits are made and the original work is properly cited (including links to both the formal publication through the relevant DOI and the license). See: https://creativecommons.org/licenses/by-nc-nd/4.0/.

\section{References}

1. Mottet N, Bellmunt J, Bolla M, et al. EAU-ESTROSIOG Guidelines on Prostate Cancer. Part 1: Screening, Diagnosis, and Local Treatment with Curative Intent. Eur Urol 2017;71:618-29.

2. National Institute Health and Care Excellence. Prostate cancer: diagnosis and management NICE guideline (NG131) Published date: 09 May 2019 United Kingdom: NICE; 2019. Available online: https://www.nice.org.uk/ guidance/ng131/chapter/Recommendations\#localisedand-locally-advanced-prostate-cancer

3. Department of Health and Welfare Victoria. Optimal care pathways for men with postate cancer Melbourne, Australia: Victorian State Government; 2014 (June 2020). Available online: https://www.cancer.org.au/healthprofessionals/optimal-cancer-care-pathways.html

4. Mohler JL, Antonarakis ES, Armstrong AJ, et al. Prostate Cancer, Version 2.2019, NCCN Clinical Practice Guidelines in Oncology. J Natl Compr Canc Netw 2019;17:479-505.

5. Bruinsma SM, Roobol MJ, Carroll PR, et al. Expert consensus document: Semantics in active surveillance for men with localized prostate cancer - results of a modified Delphi consensus procedure. Nat Rev Urol 2017;14:312-22.

6. Goh AC, Kowalkowski MA, Bailey DE Jr, et al. Perception of cancer and inconsistency in medical information are associated with decisional conflict: a pilot study of men with prostate cancer who undergo active surveillance. BJU Int 2012;110:E50-6.

7. Oliffe JL, Davison BJ, Pickles T, et al. The selfmanagement of uncertainty among men undertaking active surveillance for low-risk prostate cancer. Qual Health Res 2009; 19:432-43.

8. Volk RJ, McFall SL, Cantor SB, et al. 'It's not like you just had a heart attack': decision-making about active surveillance by men with localized prostate cancer. Psychooncology 2014;23:467-72.

9. Kinsella N, Helleman J, Bruinsma S, et al. Active surveillance for prostate cancer: a systematic review of contemporary worldwide practices. Transl Androl Urol 2018;7:83-97.

10. Kinsella N, Stattin P, Cahill D, et al. Factors Influencing Men's Choice of and Adherence to Active Surveillance for Low-risk Prostate Cancer: A Mixed-method Systematic Review. Eur Urol 2018;74:261-80.

11. Kallio H, Pietila AM, Johnson M, et al, Systematic methodological review: developing a framework for a qualitative semi-structured interview guide. J Adv Nurs 2016;72:2954-65.

12. Brinkmann S. Interviews Learning the craft of qualitative research interviews. 3rd ed. SAGE Publications; 2015.

13. Oliver DG, Serovich JM, Mason TL. Constraints and Opportunities with Interview Transcription: Towards Reflection in Qualitative Research. Soc Forces 2005;84:1273-89.

14. Department of Health UK. Research Governaance Framework for Health and Social Care. 2nd ed. 2005. Available online: https://assets.publishing.service.gov.uk/ government/uploads/system/uploads/attachment_data/ file/139565/dh_4122427.pdf

15. Hammersley M, Atkinson P. Ethnography: Principals in practice. 3rd ed. Routledge; 2007.

16. Statistics. OoN. Regional Ethnic Diversity: Office of National Statistics; 2018 (cited 2020 may 2020). Available online: https://www.ethnicity-facts-figures.service.gov. uk/uk-population-by-ethnicity/national-and-regionalpopulations/regional-ethnic-diversity/latest

17. Watts S, Leydon G, Birch B, et al. Depression and anxiety in prostate cancer: a systematic review and meta-analysis of prevalence rates. BMJ Open 2014;4:e003901. 
18. Haskard-Zolnierek K, Miller T, DiMatteo M. Promoting treatment adherence. In: al. KDe, editor. Oxford Textbook of Communication in Oncology and Palliative Care. Oxford UK: Oxford University press; 2017.

19. McIntosh M, Opozda M, Chambers S, et al. Men's experience of active surveillance: an insight into their coping strategies and the factors that influence their adherence. BJU Int 2018;122:30.

20. Hyde MK, Newton RU, Galvao DA, et al. Men's helpseeking in the first year after diagnosis of localised prostate cancer. Eur J Cancer Care (Engl) 2017;26:e12497.

21. King AJ, Evans M, Moore TH, et al. Prostate cancer and supportive care: a systematic review and qualitative synthesis of men's experiences and unmet needs. Eur J Cancer Care (Engl) 2015;24:618-34.

22. Boyle FM, Robinson E, Heinrich P, et al. Cancer: communicating in the team game. ANZ J Surg 2004;74:477-81.

23. Fuertes JN, Mislowack A, Bennett J, et al. The physicianpatient working alliance. Patient Educ Couns 2007;66:29-36.

24. Street RL Jr, Makoul G, Arora NK, et al. How does communication heal? Pathways linking clinician-patient communication to health outcomes. Patient Educ Couns 2009;74:295-301.

25. Epstein R, Street R. Patient-centered communication in cancer care: promoting healing andreducing suffering, NIH Publication No. 07-6225. In: Health NIo, editor. Bethesda, MD: National Cancer Institute; 2007.

26. Arora NK. Interacting with cancer patients: the significance of physicians' communication behavior. Soc Sci Med 2003;57:791-806.

27. Rüesch P, Schaffert R, Fischer S, et al. Information needs of early-stage prostate cancer patients: withinand between-group agreement of patients and health professionals. Support Care Cancer 2014;22:999-1007.

28. Davidson R, Mills ME. Cancer patients' satisfaction with communication, information and quality of care in a UK region. Eur J Cancer Care (Engl) 2005;14:83-90.

29. Charles C, Gafni A, Whelan T. Decision-making in the physician-patient encounter: revisiting the shared treatment decision-making model. Soc Sci Med 1999;49:651-61.

30. Hagerty RG, Butow PN, Ellis PM, et al. Communicating with realism and hope: incurable cancer patients' views on the disclosure of prognosis. J Clin Oncol 2005;23:1278-88. Erratum in: J Clin Oncol 2005;23:3652.

31. Hillen MA, de Haes HC, Smets EM. Cancer patients' trust in their physician-a review. Psychooncology 2011;20:227-41.
32. Silver JK, Baima J. Cancer prehabilitation: an opportunity to decrease treatment-related morbidity, increase cancer treatment options, and improve physical and psychological health outcomes. Am J Phys Med Rehabil 2013;92:715-27.

33. McCorkle R, Ercolano E, Lazenby M, et al. Selfmanagement: Enabling and empowering patients living with cancer as a chronic illness. CA Cancer J Clin 2011;61:50-62.

34. Coleman K, Austin BT, Brach C, et al. Evidence on the Chronic Care Model in the new millennium. Health Aff (Millwood) 2009;28:75-85.

35. Wagner EH, Austin BT, Davis C, et al. Improving chronic illness care: translating evidence into action. Health Aff (Millwood) 2001;20:64-78.

36. Lepore S. A social-cognitive processing model of emotional adjustment to cancer. In: Baum A, Andersen B, editors. Psychosocial intervention for cancer. Washington DC, USA: American Psychological Association; 2001:99-116.

37. Campbell K. The Role of Online Support Groups in Empowering Individuals affected by prostate cancer. University of Nottingham; 2012.

38. Sinfield P, Baker R, Agarwal S, et al. Patient-centred care: What are the experiences of prostate cancer patients and their partners? Patient Educ Couns 2008;73:91-6.

39. Coulter A, Ellins J. Effectiveness of strategies for informing, educating, and involving patients. BMJ 2007;335:24-7.

40. Tsianakas V, Robert G, Maben J, et al. Implementing patient-centred cancer care: using experience-based codesign to improve patient experience in breast and lung cancer services. Support Care Cancer 2012;20:2639-47. Erratum in: Support Care Cancer 2012;20:2649.

41. NHS England, Improvement N. Implementing personalised stratified followup pathways. A handbook for local health and care systems 2020. Available online: https://www.england.nhs.uk/wp-content/uploads/2020/04/ cancer-stratified-follow-up-handbook-v1-march-2020.pdf

42. Leydon GM, Boulton M, Moynihan C, et al. Cancer patients' information needs and information seeking behaviour: in depth interview study. BMJ 2000;320:909-13.

43. Hoddinott P, Pill R. Qualitative research interviewing by general practitioners. A personal view of the opportunities and pitfalls. Fam Pract 1997;14:307-12.

Cite this article as: Beckmann K, Cahill D, Brown C, Van Hemelrijck M, Kinsella N. Understanding reasons for non-adherence to active surveillance for low-intermediate risk prostate cancer. Transl Androl Urol 2021;10(6):2728-2736. doi: 10.21037/tau-20-1254 